\title{
New Science Buildings at Christ's Hospital, Horsham.
}

HIS Royal Highness the Prince of Wales, who is 1 the president of Christ's Hospital, visited the school at Horsham, on Oct. 14, to open the new buildings (Fig. 1) which have recently been erected for the purpose of supplying increased facilities for the teaching of science and geography.

The Prince arrived by aeroplane about mid-day and, accompanied by the headmaster and the Bishop of Worcester, he entered the new quadrangle, where he addressed the assembled school. In the course of his speech, he thanked those who had subscribed to the building fund and stressed the importance of biological and geographical studies in furthering the welfare of the Empire.

"The new building," he said, "which adds so finely to the beauty and usefulness of this great and ancient school, is to bo used mainly for the teaching of geography and of naturalsciences, among which, I understand, biology will now

be able to take its proper place beside chemistry and physics. Knowing as I do the need of scientific investigators to fill posts in outlying parts of the Empire, the teaching of geography and biology has for me a special appeal. They are both Imperial subjects, and they both make for the better understanding of mankind. To appreciate, through a study of biology, both the variety and the unity of all organic life is the surest path to sympathy and sound philosophy." The Prince then declared the building open and made a tour of inspection through it.

The new block of buildings is of red and white stone and forms the east side of a new quadrangle. It is very substantially built: the walls are double and the space between them filled with 'Hygean' rock-a material of bituminous nature-and the floors are of reinforced concrete.

On the ground floor are six large rooms. One is a chemical laboratory for the use of the more advanced students, leading out of which is a science library and reading-room. Two rooms are arranged for the teaching of practical mathematics, and one is a large biological laboratory. This is fitted with working benches and standing benches for aquaria, etc., and is intended for the more elementary work and nature study. It will be available for use out of school hours and will thus help to encourage the intelligent study of outdoor life, which has always been ono of the aims of the school.

On the upper floor are two large geography class-rooms. They are lofty and well lighted and have been excellently equipped under the direction of Mr. T. K. M. Booth, who is well known for his work as a teacher of physical geography. On this floor are also two other laboratories for more advanced biological work and a lecture room to accommodate about eighty boys. This is fitted with raised tiers of benches and is well equipped with up-to-date projection apparatus. Communicating with this by means of a hatch is a small preparation room.

Above one of the biological rooms is a flat roof, surrounded by a coping, where many outdoor experiments may be carried out.

The working benches in all the science rooms are of the knee hole type, and each working space is supplied with gas, water, and both high and low tension olectrical points. The constructional work has been carried out by Messrs. Henry Norris and Son, Ltd., of Hertford, under the direction of the architect, Mr. S. Tatcholl, F.R.I.B.A.

\section{Native Races of the British Empire.}

$T^{H H}$ first of the series of popular lectures under the - auspices of the Royal Anthropological Institute in the coming winter took place at the Portland Hall of the Regent Street Polytechnic Annexe on Oct. 15, when Prof. John L. Myres, president of the Royal Anthropological Institute, delivered the inaugural lecture, on "Native Races of the Empire: Facts and Problems". He said that it is remarkable, and also natural, that the greater advances in the "study of man' have occurred during the greater periods of exploration and exploitation. Contact and conflict with alien cultures sharpen men's observation of customs and beliefs, and provoke curiosity about the reasons for them. Political theories have been founded on travellers' tales ahout men in the 'state of Nature" presupposed by philosophers, and have differed like the customs so described. This has been the contribution of adventurers and administrators to anthropo- logy. What has anthropology to offer in return by way of instruction, advice, or warning to those whose interests or duties involve intercourse with " nativo races'?

At first sight, a survey of the native races of the Empire would seem to fall littlo short of a general survey of mankind, so widespread are the regions includol. But the same reasons which explain the special courses takon by colonisation and conquest determined also which races and peoples the pioneers would encounter, the historical order in which they met them, and consequently the fund of previous experience with which each fresh 'native question' was handled. This in turn suggests a natural order in which to group studies of 'native races', according to their geographical backgrounds and economic foundations.

In North Amorica, where intercourse between Furopean settlers and aboriginals occurred first on a large

No. 3182 , Vor. 126] 